\title{
Stroke rehabilitation services inadequate, experts say
}

Published at www.cmaj.ca on Mar. 18

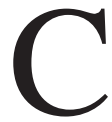
all it a tale of inadequacies inadequate facilities, beds and staff to deliver services; inadequate treatment, including outpatient services, and inadequate funding.

That litany characterizes the current state of rehabilitation programming for stroke victims across the nation, experts say.

It has created a situation in which stroke sufferers often have little option but to languish in long-term care facilities or nursing homes, says Dr. Mark Bayley, medical director of the neuro rehabilitation program at the Toronto Rehabilitation Institute in Ontario. "If some people with more severe strokes were provided with the adequate amount of rehabilitation, a certain number of them would be able to go home. This would save our health care system from having to utilize our very limited and expensive long-term care resources as much as we do currently."

Three out of every four people who have a stroke severe enough to require hospital admission fail to get sent to rehabilitation, adds Christina O'Callaghan, executive director of the Ontario Stroke Network.

The availability of rehabilitation beds and services appears to vary widely by province, and even within regions of a province, with large urban centres typically having more resources.

Canada's geography makes it difficult to provide adequate beds and services everywhere, says Linda Ross, a physiotherapist and consultant for the British Columbia Stroke Strategy. "We are so spread out and Canada has such a huge geographic footprint. Certainly there is a shortage of manpower, especially when you get to the smaller centres. It's difficult to recruit and hold people in very rural areas."

That makes it frustrating for people who live in outlying areas to get rehabilitation, says Dr. Marilyn MackayLyons, associate professor in the School

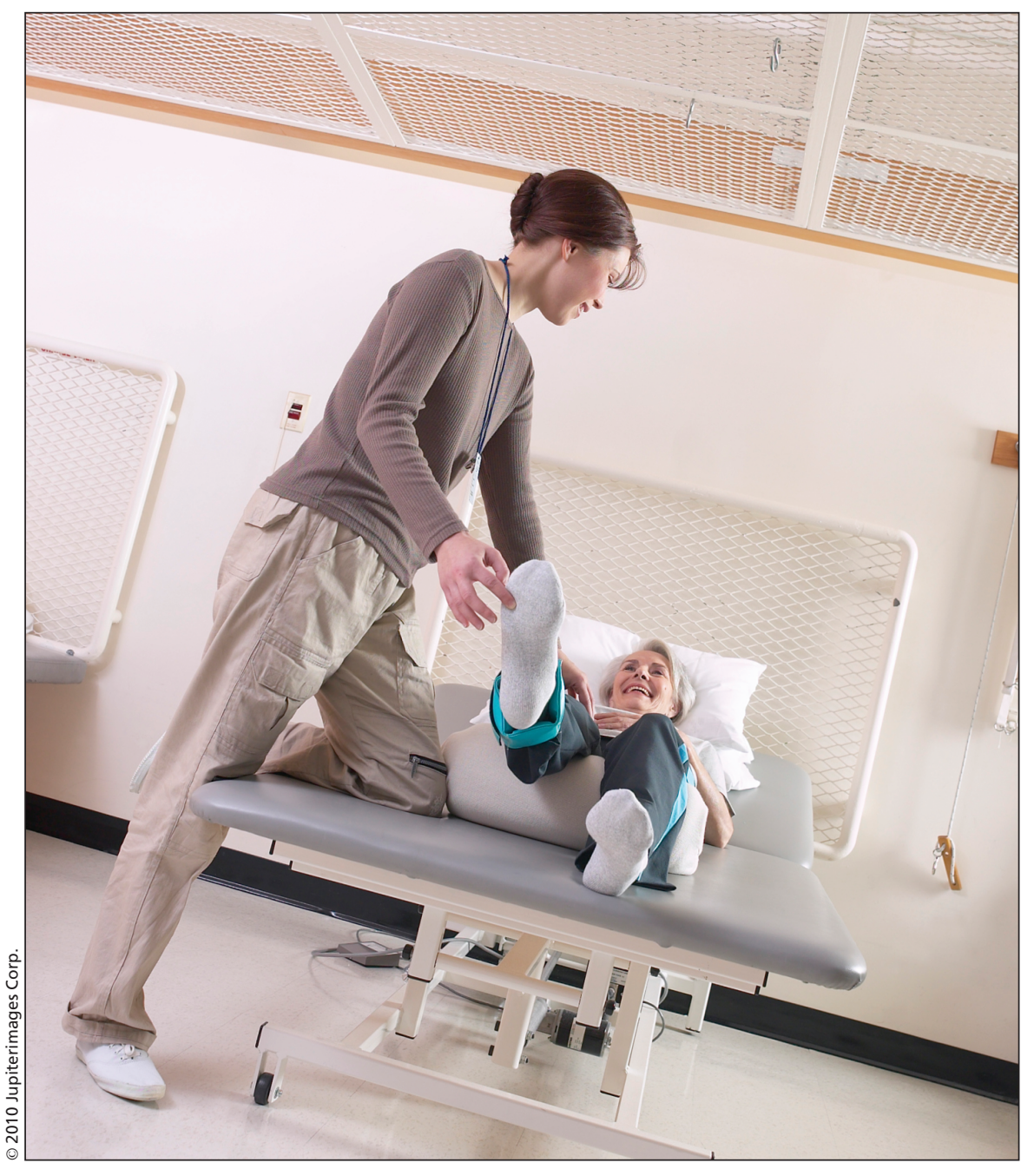

Stroke patients should ideally receive rehabilitation three hours per day, seven days a week, says Dr. Milo Fink, section head of rehabilitation medicine at the Wascana Rehabilitation Centre in Regina, Saskatchewan.

of Physiotherapy at Dalhousie University in Halifax, Nova Scotia. "I don't think this is unique to Nova Scotia or even to Canada. In part, it has to do with the nonsexiness of stroke rehab or rehabilitation in general where everyone is after the quick fix and the cure."

There are waiting lists even in parts of New Brunswick, whose Extra-Mural Program was selected as a "best practice" by the Health Council of Canada in 2007, says Jennifer Elliott, health care consultant to the province's Department of Health.
In southern Alberta, there are enough beds for people who live in Calgary and its immediate environs but not enough to handle people from southeastern British Columbia who seek care, says Dr. Stephen McNeil, a physiatrist at the Foothills Hospital. "Often they sit for months or just never get a bed, because we always have at least a short wait list."

In Ontario, access to rehabilitation beds "is reasonably good" in large cities, says Dr. Robert W. Teasell, medical director of stroke rehabilitation at 
the Parkwood Hospital in London. "We have a 30-bed stroke rehab unit in London. In smaller urban centres, access to therapy is dramatically less."

But even when beds are available, the amount of therapy that patients actually receive varies. "In London, our physiotherapist to patient ratio is 1-to7 , but in some smaller centres, it is as low as 1-to-16," says Teasell.

The ideal is for patients to receive rehabilitation three hours per day, seven days a week, says Dr. Milo Fink, section head of rehabilitation medicine at the Wascana Rehabilitation Centre in Regina, Saskatchewan. "We've been good at providing housing and meals but we've got further to go in terms of getting our patients up and moving and engaged. We don't give our patients enough therapy. If we gave them the right number of hours per day, I believe that people would get better faster."

Outpatient services also appear to vary across the country.

In $\mathrm{BC}$, patients can wait for six months for outpatient services, long enough to practically make rehab use- less, says Dr. Jennifer K. Yao, medical manager of the acquired brain injury program at the GF Strong Rehabilitation Centre in Vancouver.

Outpatient services in Quebec must also be improved, says Linda Pichard, director of adult rehabilitation at the Institut de Réadaptation en Deficience Physique de Québec. "It's not as good as it could be."

McNeil says Calgary's outpatient services are "a big area of concern, even within the big cities. We often keep people as inpatients just so they can access more intensive therapies."

Outpatient services are often the first casualty of budget-cutting exercises, says Elizabeth Woodbury, executive director for the Canadian Stroke Strategy. "This is counterproductive for stroke rehabilitation. Outpatient services for some patients can be more efficient than inpatient services. To the extent that they don't exist, we are limiting capacity and available options. Unfortunately, that can result in patients not having access to effective stroke rehabilitation at all."
Funding decisions often affect services, McNeil says. "Alberta realized the importance of the rehab side of things much more than Ontario did. For example, where Ontario put almost no money towards rehab, Alberta put a significant amount of our stroke strategy budget towards rehab. Ontario has its stroke strategy as well but most of their funding went to neurology for acute stroke services."

Similarly, Teasell notes that "about 10 years ago, the Ontario Stroke Strategy invested heavily in prevention and acute care and delivery of the clot busting drug tPA, with great results. But it never invested in rehabilitation per se. Only about $6 \%$ was spent on rehab and community care. This reflects how the health care system views chronic illness. The high tech 'blood and guts' is prioritized while rehab, which is 'low tech high touch' is not given a lot of attention, except by patients who value that part of their treatment the most." - Fran Lowry, Toronto, Ont.

DOI:10.1503/cmaj.109-3214 